\title{
Competitive location: a state-of-art review
}

\author{
Milad Gorji Ashtiani*
}

Department of Industrial Engineering, Iran University of Science and Technology, Narmak, Tehran, Iran

\begin{tabular}{l}
\hline C H R O N I C L E \\
\hline Article history: \\
Received April 202015 \\
Received in Revised Format \\
July 232015 \\
Accepted August 122015 \\
Available online \\
August 14 2015 \\
\hline Keywords: \\
Facility location \\
Competitive location \\
Inelastic \\
Elastic \\
Continuous \\
Discrete
\end{tabular}

\section{A B S T R A C T}

This paper provides a review on recent works in the field of competitive facility location models based on the following seven components: 1) Variables, 2) Competition type, 3) Solution space, 4) Customer behavior, 5) Demand type, 6) Number of new facilities and 7) Relocation and redesign possibility. First, the components are introduced and then based on these components; different studies are compared with each other via a proposed taxonomy and finally a review on work of each paper is provided.

\section{Introduction}

The aim of location models is to find optimal location for one or more new facilities with a specific objective such as total cost minimization, overall profit maximization, etc. Location theory is very widespread and entails with several issues. The vast part of this theory embraces "Location" under monopoly condition in which a chain captures the market, dominantly (Ashtiani et al., 2011). In this case, a set of facilities that is going to be located, supply products or services and the ownership of all facilities belongs to one person or one company that has no competitor in the market. The review of this kind of researches is carried out by Drezner (1995). Practically, the respective models are not normally applicable for real-world cases because a company rarely acts as the only player in the market and competition among different players seems to be more realistic (Ashtiani et al., 2013). 
A location model is classified into competitive facilities when it clearly states that other facilities are already/will be present in the market and that the new facility/facilities will ought to compete with them for its/their necessary market share (Plastria, 2001).

Hotelling (1929) is believed the first who introduced the idea of competitive facility location models by studying the strategies of two competitors in terms of price and location under various assumptions. Since then, all researchers have used the closest facility in Hotelling model. Huff (1964) described the attractive function of facility for customers by taking into account not only the distance but also the design of facility. He formulated a model for capturing market share by considering the probability of customer patronizing behavior towards a facility and the likelihood is depends on the design of the facility and it is also inversely associated with the squared distance between a facility and a customer.

After these seminal works, a flow of researches in this field has been introduced and over the years this has been dramatically increased. The increasing interest in competitive facility location model is not only depends on vastly increased computational power and algorithmic knowledge but also depends on the increased number of applications (Eiselt et al., 1993).

This paper gives an overview of competitive facility location papers from 2000 to 2015. There are, at least, three journal papers reviewing the literature regarding competitive facility location models (Eiselt et al., 1993; Plastria, 2001; Drezner, 2014). Since Eiselt et al. (1993) and Plasteria (2001) reviewed the literature up to 2000, this paper extends them by surveying different competitive facility location approaches through a literature review and classification of the international journal papers from 2000 to present. The structure of this review paper is totally different from the work accomplished by Drezner (2014). This paper focuses more on classification for categorizing different models.

We focus our attention towards those competitive location models which are in "continuous \& discrete spaces" and also "static \& competition with foresight area". In other words, because of different characteristics of "network" space and "dynamic competition", competitive location models which use these assumptions have been excluded in this review. This literature review tries to answer the following questions,

1-What are the decision variables of the problem?

2-What is the competition type of the model?

3-What is the solution space of the model?

4-What is the customer patronizing behavior of the problem?

5-What is the demand type of the model?

6-How many new facilities will be located in the problem?

7-Are/Is relocation and/or redesign of existing facilities possible in the problem?

Based on the above seven categorization, different studies under various assumptions have been considered. For instance, one paper investigated one specific model in the continuous space and the other presented the same model in a discrete space. Papers with the same seven proposed components may be different in various things like solution method, objective function, single objective or multiple objectives, distance type (Euclidean, rectangular, ...), being variable or parameter for number of new facilities and etc. This paper is organized as follows: In section 2, seven components of the proposed classification are introduced. Different papers are labeled in an annotated bibliography format in section 3. Section 4 briefly describes works of each paper and finally conclusions and suggestions for future research are proposed in section 5.

\section{Competitive facility location models components}

In this section, major components of competitive location models are introduced. Based on this discussion a classification is proposed: 7-tuple (1)-(2)-(3)-(4)-(5)-(6)-(7), where 
1) Identifies variable of problem;

3) Specifies solution space;

5) Determines demand type;

7) Displays relocation and redesign possibility.
2) States competition type;

4) Indicates customer behavior;

6) Depicted number of new facilities;

These components are briefly discussed in the following subsections.

\subsection{Variable of problem}

\subsubsection{Location}

Surely, detecting the optimal location of the problem is the primary decision variable within the concept of the location theory. Therefore, in the field of competitive location, if there are no other variables, the only decision variable of the problem is location.

\subsubsection{Location and Design}

The full questions to be answered by the model may involve more than the location. Many researchers are recently interested in the studies and models where the primary objective is to determine the optimal design of new facilities in addition to the location of them.

\subsubsection{Location and Price}

In addition to the location, another variable of some models is associated with the price of goods or services of facilities. Pricing has been investigated for the past few years. Nowadays, pricing is less used in the field of competitive location

\subsubsection{Location and other variables}

During the recent years, some other variables have been used in addition to location such as capacity, routing, size and shipment.

\subsection{Competition type}

\subsubsection{Static competition}

The simplest competitive models occurs when competition is assumed to be already present in the market. The whereabouts and characteristics of this competition are known in advance and assumed to be fixed. The basic assumption in such models is that the competitive factors of the existing competitors are not permitted to change following the new competitor's entrance. Such models involve only strategic decisions.

\subsubsection{Competition with foresight}

The situation becomes quite different when a virgin market is entered in the knowledge that other competing actors will enter it soon afterwards. It will then be essential to make decisions with foresight about by considering this competition, which itself will enter a market where competition is already present. The ensuing Stackelberg-type models, where each evaluation of the main objective involves the solution of the competitor's nontrivial optimization model, become extremely complex. The primary assumption in competition with foresight is that a competitor (a follower) will enter the market following the entrance of our facility (the leader). The leader's decisions are based on the follower's action. In these models the likely impact of future competition must be considered. 
2.3 Solution space

\subsubsection{Discrete space}

In discrete space, there is only a (relatively small) finite list of candidate sites for opening new facilities.

\subsubsection{Continuous space}

Continuous space is associated with a locational space determined by a coordinate system in which in principle any real coordinate values are permitted. One-dimensional space is equivalent to the linear segment (or line), a very popular setting for competitive equilibrium studies in virtue of its simplicity. Other settings are of course the geographical space modelled as a two-dimensional plane or possibly a sphere.

\subsection{Customer behavior}

\subsubsection{Closest rule}

The assumption that consumers patronize the facility closest to them means that the competing facilities are equally attractive or that consumers consider only distance in their selection. The closest rule is suitable either for central planning where planners allocate demand to facilities, or for public facilities, or when consumers are highly price sensitive and will always choose the cheapest option.

\subsubsection{Deterministic utility rule}

When the facilities are not equally attractive, the closest rule for allocating consumers to facilities does not hold any more. To account for variations in facility attractiveness, a deterministic utility approach can be implemented. The choice is deterministic when the full demand of each customer is served by the facility in which it is attracted the most. Basically it assumes that as long as the facility remains unchanged customers will always patronize the facility.

\subsubsection{Probabilistic utility rule}

A deterministic choice rule does not allow for the "changing mood" of customers. The choice is probabilistic when each customer splits its volume of demand on various facilities, with probabilities determined some way by the attraction felt towards each facility. Most competitive location problems with probabilistic choice rule have recently implemented huff-based models. Huff proposed that the probability that a consumer patronizes a retail facility (a mall) is associated with its size (floor area) and inversely related to a power of the distance to it.

\subsubsection{Cover-based rule}

In cover-based approach, each competing facility has a "sphere of influence” represented by a radius of influence which relies on the attractiveness of the facility. A consumer at a distance within the radius of influence is absorbed to the facility and his/her demand within the sphere of influence of no facility can be lost.

\subsection{Demand type}

\subsubsection{Inelastic demand}

It is customary to consider demand for essential goods such as bread to be inelastic (within time-periods during which populations may be considered as constant). 


\subsubsection{Elastic demand}

In contrast to the inelastic demand, another type of demand is elastic for inessential e.g., luxury, commodities for which demand may be highly supply/price sensitive.

\subsection{Number of new facilities}

\subsubsection{Single facility}

The number of new facilities to locate strongly influences the difficulty of the model. In some competitive location papers, the model looks for optimal location (or design) for single new facility.

\subsubsection{Multiple facilities}

The aim of some papers in the field of competitive facility location is to find the optimal location (or design) for multiple new facilities. In models with foresight one also distinguishes with respect to the number of (future) competing facilities. Models in which the number of new facilities is not fixed are also included in this category.

\subsection{Relocation and redesign possibility}

In most competitive facility location models, it is assumed that the chain and its competitors maximize their market share by opening new facilities and the location and design of their existing facilities are not changed at all. The vast portion of competitive location models has not been considered relocation and/or redesign of existing facilities.

\section{Annotated bibliography}

All the reviewed papers are compared by different proposed components. In summary, the components in the suggested classification are:

1) Variable of problem
a) Location (L)
b) Location-design (L-D)
c) Location-price (L-P)
d) Location-other variables (L-O)

2) Competition type
a) Static (S)
b) With foresight $(\mathrm{F})$

3) Solution space
a) Discrete (D)
b) Continuous (C)

4) Customer behavior
a) Closest (C)
b) Deterministic utility (D)
c) Probabilistic utility (P)
d) Cover-based (Co)

5) Demand type
a) Inelastic (I)
b) Elastic (E)

6) Number of new facilities

a) Single (S)

b) Multiple (M)

7) Relocation and/or redesign possibility

a) Yes (Y)

b) No $(\mathrm{N})$

The bibliography of Table 1 lists and codes of different papers according to this classification. 
Table 1

Codes of different papers

\begin{tabular}{|c|c|c|c|}
\hline Paper & Code of paper & Paper & Code of paper \\
\hline Aboolian et al. (2007a) & $(\mathrm{L}-\mathrm{D})-(\mathrm{S})-(\mathrm{D})-(\mathrm{P})-(\mathrm{E})-(\mathrm{M})-(\mathrm{N})$ & Aboolian et al. (2007b) & $(\mathrm{L})-(\mathrm{S})-(\mathrm{D})-(\mathrm{P})-(\mathrm{E})-(\mathrm{M})-(\mathrm{N})$ \\
\hline Aboolian et al. (2008) & (L-P)-(S)-(D)-(D)-(E)-(M)-(N) & Aboolian et al. (2009) & (L)-(S)-(D)-(P)-(I)-(M)-(N) \\
\hline Alekseeva et al. (2013) & $(\mathrm{L})-(\mathrm{F})-(\mathrm{D})-(\mathrm{C})-(\mathrm{I})-(\mathrm{M})-(\mathrm{N})$ & Arrondo et al. (2014a) & $(\mathrm{L}-\mathrm{D})-(\mathrm{S})-(\mathrm{C})-(\mathrm{P})-(\mathrm{E})-(\mathrm{S})-(\mathrm{N})$ \\
\hline Arrondo et al. (2014b) & $(\mathrm{L}-\mathrm{D})-(\mathrm{F})-(\mathrm{C})-(\mathrm{P})-(\mathrm{E})-(\mathrm{S})-(\mathrm{N})$ & Arrondo et al. (2015) & $(\mathrm{L}-\mathrm{D})-(\mathrm{S})-(\mathrm{C})-(\mathrm{P})-(\mathrm{I})-(\mathrm{M})-(\mathrm{N})$ \\
\hline Ashtiani et al. (2011) & $(\mathrm{L})-(\mathrm{F})-(\mathrm{D})-(\mathrm{P})-(\mathrm{I})-(\mathrm{M})-(\mathrm{N})$ & Ashtiani et al. (2013) & $(\mathrm{L})-(\mathrm{F})-(\mathrm{D})-(\mathrm{P})-(\mathrm{I})-(\mathrm{M})-(\mathrm{N})$ \\
\hline Bello et al. (2011) & $(\mathrm{L})-(\mathrm{S})-(\mathrm{C})-(\mathrm{P})-(\mathrm{I})-(\mathrm{S})-(\mathrm{N})$ & Benati \& Hansen (2002) & (L)-(S)-(D)-(P)-(I)-(M)-(N) \\
\hline Beresnev (2009) & (L)-(F)-(D)-(D)-(I)-(M)-(N) & Beresnev (2012) & (L)-(F)-(D)-(D)-(I)-(M)-(N) \\
\hline Beresnev (2013) & $(\mathrm{L})-(\mathrm{F})-(\mathrm{D})-(\mathrm{D})-(\mathrm{I})-(\mathrm{M})-(\mathrm{N})$ & Beresnev \& Mel'nikov (2011) & $(\mathrm{L})-(\mathrm{F})-(\mathrm{D})-(\mathrm{D})-(\mathrm{I})-(\mathrm{M})-(\mathrm{N})$ \\
\hline Berman \& Krass (2002) & (L)-(S)-(D)-(P)-(E)-(M)-(N) & Bhadury et al. (2003) & $(\mathrm{L})-(\mathrm{F})-(\mathrm{C})-(\mathrm{C})-(\mathrm{I})-(\mathrm{M})-(\mathrm{N})$ \\
\hline Bhattacharya \& Nandy (2013) & (L)-(S)-(C)-(C)-(I)-(M)-(N) & Biesinger et al. (2014a) & (L)-(F)-(D)-(C)-(I)-(M)-(N) \\
\hline Biesinger et al. (2014b) & (L)-(F)-(D)-(P)-(I)-(M)-(N) & Biesinger et al. (2014c) & (L)-(F)-(D)-(C)-(I)-(M)-(N) \\
\hline Bozkaya et al. (2010) & $(\mathrm{L}-\mathrm{O})-(\mathrm{S})-(\mathrm{D})-(\mathrm{P})-(\mathrm{E})-(\mathrm{M})-(\mathrm{Y})$ & Dasci \& Laporte (2005) & $(\mathrm{L})-(\mathrm{F})-(\mathrm{C})-(\mathrm{C})-(\mathrm{I})-(\mathrm{M})-(\mathrm{N})$ \\
\hline Davydov et al. (2014a) & $(\mathrm{L})-(\mathrm{F})-(\mathrm{C})-(\mathrm{C})-(\mathrm{I})-(\mathrm{M})-(\mathrm{N})$ & Davydov et al. (2014b) & (L)-(F)-(D)-(C)-(I)-(M)-(N) \\
\hline Drezner (2009) & $(\mathrm{L})-(\mathrm{S})-(\mathrm{C})-(\mathrm{P})-(\mathrm{I})-(\mathrm{S})-(\mathrm{N})$ & Drezner (2010) & $(\mathrm{L})-(\mathrm{S})-(\mathrm{C})-(\mathrm{P})-(\mathrm{I})-(\mathrm{S})-(\mathrm{N})$ \\
\hline Drezner \& Drezner (2002) & $\begin{array}{l}\text { (L)-(F)-(C)-(P)-(I)-(S)-(N) } \\
(\mathrm{L})-(\mathrm{S})-(\mathrm{C})-(\mathrm{P})-(\mathrm{I})-(\mathrm{S})-(\mathrm{N})\end{array}$ & Drezner \& Drezner (2012) & $\begin{array}{l}(\mathrm{L})-(\mathrm{S})-(\mathrm{C})-(\mathrm{C})-(\mathrm{E})-(\mathrm{M})-(\mathrm{N}) \\
(\mathrm{L})-(\mathrm{S})-(\mathrm{C})-(\mathrm{P})-(\mathrm{E})-(\mathrm{M})-(\mathrm{N})\end{array}$ \\
\hline Drezner \& Drezner (2004) & $(\mathrm{L})-(\mathrm{S})-(\mathrm{C})-(\mathrm{P})-(\mathrm{I})-(\mathrm{S})-(\mathrm{N})$ & Drezner \& Drezner (2008) & $(\mathrm{L})-(\mathrm{S})-(\mathrm{C})-(\mathrm{P})-(\mathrm{E})-(\mathrm{S})-(\mathrm{N})$ \\
\hline Drezner \& Drezner (2014) & $(\mathrm{L})-(\mathrm{S})-(\mathrm{C})-(\mathrm{P})-(\mathrm{I})-(\mathrm{S})-(\mathrm{N})$ & Drezner et al. (2011) & $(\mathrm{L})-(\mathrm{S})-(\mathrm{D})-(\mathrm{Co})-(\mathrm{E})-(\mathrm{M})-(\mathrm{N})$ \\
\hline Drezner et al. (2012) & (L-D)-(S)-(D)-(Co)-(E)-(M)-(Y) & Drezner et al. (2015) & (L)-(F)-(D)-(Co)-(I)-(M)-(Y) \\
\hline Drezner et al. (2002a) & $(\mathrm{L})-(\mathrm{S})-(\mathrm{C})-(\mathrm{P})-(\mathrm{I})-(\mathrm{M})-(\mathrm{N})$ & Drezner et al. (2002b) & (L)-(S)-(C)-(P)-(I)-(S)-(N) \\
\hline Drezner et al. (2007) & (L)-(S)-(C)-(D)-(I)-(M)-(N) & Fernández et al. (2007a) & $(\mathrm{L}-\mathrm{D})-(\mathrm{S})-(\mathrm{C})-(\mathrm{D})-(\mathrm{I})-(\mathrm{S})-(\mathrm{N})$ \\
\hline Fernández et al. (2007b) & (L-D)-(S)-(C)-(P)-(I)-(S)-(N) & & $(\mathrm{L}-\mathrm{D})-(\mathrm{S})-(\mathrm{C})-(\mathrm{P})-(\mathrm{I})-(\mathrm{S})-(\mathrm{N})$ \\
\hline Fernández et al. (2014) & (L-P)-(F)-(C)-(D)-(I)-(M)-(N) & Fernández et al. (2006) & $(\mathrm{L}-\mathrm{D})-(\mathrm{S})-(\mathrm{C})-(\mathrm{P})-(\mathrm{I})-(\mathrm{S})-(\mathrm{N})$ \\
\hline Fischer (2002) & (L-P)-(F)-(D)-(D)-(E)-(M)-(N) & Fu et al. (2013) & (L)-(S)-(C)-(C)-(I)-(M)-(N) \\
\hline Godinho \& Dias (2010) & $(\mathrm{L})-(\mathrm{F})-(\mathrm{D})-(\mathrm{C})-(\mathrm{I})-(\mathrm{M})-(\mathrm{N})$ & Godinho \& Dias (2013) & (L)-(F)-(D)-(C)-(I)-(M)-(N) \\
\hline Hendrix (2015) & (L-D)-(F)-(C)-(D)-(I)-(S)-(N) & Kononov et al. (2009) & (L)-(F)-(D)-(D)-(I)-(M)-(N) \\
\hline Konur \& Geunes (2012) & (L-O)-(S)-(D)-(D)-(I)-(M)-(N) & Küçükaydın et al. (2011a) & (L-D)-(S)-(D)-(P)-(I)-(M)-(N) \\
\hline Küçükaydın et al. (2011b) & $(\mathrm{L}-\mathrm{D})-(\mathrm{F})-(\mathrm{D})-(\mathrm{P})-(\mathrm{I})-(\mathrm{M})-(\mathrm{Y})$ & Küçükaydın et al. (2012) & $(\mathrm{L}-\mathrm{D})-(\mathrm{F})-(\mathrm{D})-(\mathrm{P})-(\mathrm{I})-(\mathrm{M})-(\mathrm{Y})$ \\
\hline Kwasnica \& Stavrulaki (2008) & $(\mathrm{L}-\mathrm{O})-(\mathrm{F})-(\mathrm{C})-(\mathrm{D})-(\mathrm{E})-(\mathrm{S})-(\mathrm{N})$ & Lančinskas et al. (2014) & $(\mathrm{L}-\mathrm{D})-(\mathrm{S})-(\mathrm{C})-(\mathrm{P})-(\mathrm{I})-(\mathrm{S})-(\mathrm{N})$ \\
\hline Lee \& O’Kelly (2011) & $(\mathrm{L})-(\mathrm{S})-(\mathrm{D})-(\mathrm{C})-(\mathrm{E})-(\mathrm{M})-(\mathrm{N})$ & McGarvey \& Cavalier (2005) & $(\mathrm{L})-(\mathrm{S})-(\mathrm{C})-(\mathrm{P})-(\mathrm{E})-(\mathrm{M})-(\mathrm{N})$ \\
\hline Mel’nikov (2014) & $(\mathrm{L})-(\mathrm{F})-(\mathrm{D})-(\mathrm{D})-(\mathrm{I})-(\mathrm{M})-(\mathrm{N})$ & Miliotis et al. (2002) & (L)-(S)-(D)-(Co)-(I)-(M)-(N) \\
\hline MirHassani et al. (2015) & $(\mathrm{L})-(\mathrm{F})-(\mathrm{D})-(\mathrm{D})-(\mathrm{I})-(\mathrm{M})-(\mathrm{N})$ & Panin et al. (2014) & $(\mathrm{L}-\mathrm{P})-(\mathrm{F})-(\mathrm{D})-(\mathrm{D})-(\mathrm{E})-(\mathrm{M})-(\mathrm{N})$ \\
\hline Pelegrín et al. (2014) & (L)-(S)-(D)-(D)-(I)-(M)-(N) & Pelegrín et al. (2012) & (L-P)-(S)-(D)-(D)-(E)-(M)-(N) \\
\hline Pérez et al. (2004) & (L-P)-(S)-(C)-(D)-(I)-(M)-(N) & Plastria (2005) & (L)-(S)-(C)-(D)-(I)-(S)-(N) \\
\hline Plastria \& Carrizosa (2004) & (L-D)-(S)-(C)-(D)-(I)-(S)-(N) & \multirow{2}{*}{ Plastria \& Vanhaverbeke (2007) } & (L)-(S)-(D)-(C)-(I)-(S)-(N) \\
\hline Plastria \& Vanhaverbeke (2008) & $(\mathrm{L})-(\mathrm{F})-(\mathrm{D})-(\mathrm{C})-(\mathrm{I})-(\mathrm{S})-(\mathrm{N})$ & & (L)-(F)-(D)-(C)-(I)-(S)-(N) \\
\hline Rahmani \& Yousefikhoshbakht (2012) & (L)-(F)-(D)-(D)-(I)-(M)-(N) & Ramezanian \& Ashtiani (2011) & (L)-(F)-(D)-(P)-(I)-(M)-(N) \\
\hline Redondo et al. (2013) & $(\mathrm{L}-\mathrm{D})-(\mathrm{F})-(\mathrm{C})-(\mathrm{P})-(\mathrm{E})-(\mathrm{S})-(\mathrm{N})$ & Redondo et al. (2012) & $(\mathrm{L}-\mathrm{D})-(\mathrm{S})-(\mathrm{C})-(\mathrm{P})-(\mathrm{E})-(\mathrm{S})-(\mathrm{N})$ \\
\hline Redondo et al. (2008) & $(\mathrm{L}-\mathrm{D})-(\mathrm{S})-(\mathrm{C})-(\mathrm{P})-(\mathrm{I})-(\mathrm{S})-(\mathrm{N})$ & Redondo et al. (2009a) & $(\mathrm{L}-\mathrm{D})-(\mathrm{S})-(\mathrm{C})-(\mathrm{P})-(\mathrm{I})-(\mathrm{S})-(\mathrm{N})$ \\
\hline Redondo et al. (2009b) & (L-D)-(S)-(C)-(P)-(I)-(M)-(N) & Redondo et al. (2009c) & $(\mathrm{L}-\mathrm{D})-(\mathrm{S})-(\mathrm{C})-(\mathrm{P})-(\mathrm{I})-(\mathrm{M})-(\mathrm{N})$ \\
\hline Redondo et al. (2010) & (L-D)-(F)-(C)-(P)-(I)-(S)-(N) & Redondo et al. (2014) & (L-D)-(S)-(C)-(P)-(I)-(M)-(N) \\
\hline Saidani et al. (2012) & $(\mathrm{L}-\mathrm{D})-(\mathrm{F})-(\mathrm{C})-(\mathrm{P})-(\mathrm{I})-(\mathrm{S})-(\mathrm{N})$ & Sáiz et al. (2009) & $(\mathrm{L})-(\mathrm{F})-(\mathrm{C})-(\mathrm{P})-(\mathrm{I})-(\mathrm{S})-(\mathrm{N})$ \\
\hline Sáiz et al. (2011) & $(\mathrm{L}-\mathrm{D})-(\mathrm{F})-(\mathrm{C})-(\mathrm{P})-(\mathrm{I})-(\mathrm{S})-(\mathrm{N})$ & Shiode et al. (2009) & $(\mathrm{L})-(\mathrm{F})-(\mathrm{C})-(\mathrm{C})-(\mathrm{E})-(\mathrm{M})-(\mathrm{N})$ \\
\hline Shiode et al. (2012) & $(\mathrm{L})-(\mathrm{F})-(\mathrm{C})-(\mathrm{C})-(\mathrm{I})-(\mathrm{S})-(\mathrm{N})$ & Tóth et al. (2009) & $(\mathrm{L}-\mathrm{D})-(\mathrm{S})-(\mathrm{C})-(\mathrm{P})-(\mathrm{I})-(\mathrm{M})-(\mathrm{N})$ \\
\hline Uno et al. (2009) & (L)-(S)-(C)-(D)-(I)-(M)-(N) & Uno et al. (2010) & (L)-(S)-(C)-(D)-(I)-(M)-(N) \\
\hline Uno et al. (2011) & $(\mathrm{L})-(\mathrm{S})-(\mathrm{C})-(\mathrm{P})-(\mathrm{I})-(\mathrm{M})-(\mathrm{N})$ & Wang \& Ouyang (2013) & $(\mathrm{L}-\mathrm{D})-(\mathrm{F})-(\mathrm{D})-(\mathrm{C})-(\mathrm{E})-(\mathrm{M})-(\mathrm{N})$ \\
\hline Wang et al. (2008) & (L)-(S)-(D)-(P)-(E)-(M)-(Y) & Zhang \& Rushton (2008) & $(\mathrm{L}-\mathrm{O})-(\mathrm{S})-(\mathrm{C})-(\mathrm{P})-(\mathrm{I})-(\mathrm{M})-(\mathrm{Y})$ \\
\hline
\end{tabular}

\section{Papers review}

In this section, different works in the field of competitive location is briefly described. This section is divided into sub sections according to the proposed classification.

\subsection{Location models in static environment}

The vast part of competitive location models has considered pure location models in a static environment. Each paper has considered a set of assumptions and introduced a new problem.

\subsubsection{Models with inelastic demand}

\section{Continuous models}

Drezner and Drezner (2004) solved the Huff model for single new facility location problem. They showed that the generalized Weiszfeld procedure converges to a local maximum or a saddle point. They also devised a global optimization procedure that finds the optimal solution within a given accuracy. Drezner et al. (2002a) proposed five heuristic procedures for the solution of the multiple competitive facilities 
location of the same problem. They performed extensive computational tests and concluded that a twostep heuristic procedure combining simulated annealing and an ascent algorithm provides the best solutions.

Drezner et al. (2007) investigated the location of multiple facilities with deterministic utility rule. They generated a set of candidate locations and solved the single facility problem by evaluating the buying power attracted to the new facility at each candidate location. They then solved the location of multiple facilities by converting the problem to a maximum covering problem.

Bhattacharya and Nandy (2013) considered a single new facility competitive location model such that a number of users served by the new facility are maximized. Each user takes service from its nearest facility, where the distance between a pair of points is measured in either $L_{1}$ or $L_{2}$ or $L_{\infty}$ metric. Fu et al. (2013) studied the similar problem on the plane according to Manhattan distance. For this problem with binary customer preferences, i.e., a case where customers choose the closest facility to satisfy their entire demand, they showed that the general problem is NP-hard and presented solution methods to solve various special cases in polynomial time.

Uno et al. (2009) proposed a problem with uncertain demands in the plane. By representing the demands for facilities as random variables, the location problem has been formulated to a stochastic programming problem, and for finding its solution, three deterministic programming problems: expectation maximizing problem, probability maximizing problem, and satisfying level maximizing problem have been considered. In another work, the authors proposed with uncertainty and vagueness including demands for the facilities in a plane (Uno et al., 2010). By representing the demands for facilities as fuzzy random variables, the location problem has been formulated as a fuzzy random programming problem. For solving the problem, first the $\alpha$-level sets for fuzzy numbers have been used for transforming it to a stochastic programming problem, and then, by using their expectations and variances, the problem is reformulated to a deterministic programming problem.

Drezner and Drezner (2002) investigated the location of retail facilities under changing market conditions when market conditions are expected to change during the planning horizon. Three models have been presented: (1) the minimax regret model, (2) the Stackelberg equilibrium model, and (3) the threshold model. Their objective is to minimize the probability of failure. Drezner (2009) incorporated future market conditions into the minimax regret model in Drezner and Drezner (2002) for the location of a retail facility. Future market conditions have been analyzed as a set of different scenarios. The problem of finding the best location for a new retail facility such that the market share captured at that location is as close to the maximum as possible in spite of the future scenarios. Bello et al. (2011) addressed the similar location problem in Drezner and Drezner (2002). Uncertainty exists on the buying power of the customers. This has been modeled by assuming that a set of scenarios exists, each scenario corresponding to a weight realization. The objective is to locate the facility following the Savage criterion, i.e., the minimax-regret location has been sought. The problem has been formulated as a global optimization problem with objective written as difference of two convex monotonic functions.

Drezner et al. (2002b) considered a location model based on the threshold concept and determined the best location such that the probability of revenue falling short of the threshold could be minimized. This objective is appropriate when a firm will not survive if its revenue falls below a known threshold. They sought the location in which the probability that the revenue is below a given threshold is minimized. Plastria (2005) studied the lexicographic optimization problem with primary objective to maximize the total market share of the chain and secondarily to minimize the market losses of friendly facilities and/or the risk that competing facilities would raise their current quality in order to gain back lost customers for a single new facility and deterministic utility rule. Drezner (2010) studied cannibalization and its effects on location decisions in a similar model. The authors analyzed maximizing market share while minimizing cannibalization using the huff model. The efficient frontier according to these two noncompatible objectives has been built and demonstrated on an example problem. 
Uno et al. (2011) considered competitive facility location problems on multi-dimensional spaces. In order to solve the formulated problem efficiently, first, it has been demonstrated that one of its optimal solutions can be determined by solving a 0-1 programming problem, next, its efficient solution method was proposed based on tabu search algorithm with strategic oscillation. Drezner and Drezner (2014) investigated sequential location of two facilities. One strategy was to locate the first facility at its single facility optimum and the second strategy was to randomly locate the first facility. The second facility was then located at its optimal location given the first facility's location. They investigated which of these two strategies is better.

\section{Discrete models}

Aboolian et al. (2009) presented efficient solution approaches for multi-facility competitive model with probabilistic patronizing behavior. Applying the concept of “Tangent Line Approximation", they developed efficient computational approaches both exact and approximate solutions. Benati and Hansen (2002) introduced a model for the optimal location of new facilities under the hypothesis that customers' behavior can be formulated by random utility functions. Therefore the company cannot forecast the behavior of every customer in a deterministic fashion, but is able to embed him/her by a probability distribution. Three formulations were proposed to compute upper bounds of the objective function. A branch and bound method was developed for medium sized problems and a Variable Neighborhood Search heuristic has been proposed to solve larger instances.

Pelegrín et al. (2014) considered a similar model to Plastria (2005) for multiple new facilities in discrete space. They used the weighted method to develop an integer linear programming model to obtain Pareto optimal locations associated with the inner competition between the owners of the old facilities and the owners of the new facilities. Miliotis et al. (2002) explained how demand-covering models could be combined with geographical information systems (GIS) to determine the optimal location of bank branches, taking into account the different factors that characterize local conditions within the demand area.

Plastria and Vanhaverbeke (2007) presented a preprocessing aggregation method to reduce the number of demand points which prevents the loss of information, and therefore prevents the possible loss of optimality. It is specifically effective in the frequent situation with a large number of demand points and a comparatively low number of potential facility sites, and coverage defined by spatial nearness.

\subsubsection{Models with elastic demand}

\section{Continuous models}

Drezner and Drezner (2008) constructed a model that considers a decline in demand as a function of the distance to competing facilities. If the competing facilities are close to the customers, a larger portion of the buying power will be spent at these facilities. Two objectives have been considered. One is the maximization of the buying power spent at all competing facilities, and the second is the maximization of the buying power captured by one's chain of retail facilities. After that, the authors proposed a simple approach to model elastic demand in competitive facility location (Drezner \& Drezner, 2012). A 'dummy' competing facility that attracts the lost demand is added to the list of competing facilities.

McGarvey and Cavalier (2005) presented a huff-based utility model, in which the capacity of a facility serves as its measure of attractiveness. Problem formulation incorporates elastic huff-based demand, along with capacity, forbidden region, and budget constraints. Two solution algorithms have been presented, one based on the big square small square method, and the second one based on a penalty function formulation using fixed-point iteration. 


\section{Discrete models}

Berman and Krass (2002) developed a new framework for location of competitive facilities by introducing non-constant expenditure functions into location models. This framework permits capturing two key effects-market expansion and cannibalization-within the same model. They developed algorithmic methods for locating optimal or near-optimal solutions. After that, Aboolian et al. (2007b) considered the similar model. Customer demand was assumed to be a concave non-decreasing function of the total utility derived by each customer from the service offered by the facilities. The problem was formulated as a non-linear Knapsack problem and developed a fast heuristic algorithm for solving the problem. Drezner et al. (2011) proposed another approach for estimating market share based on cover location models. In their model, each facility had a 'sphere of influence' detected by its attractiveness level and the buying power of a customer within the sphere of influence of no facility could be lost.

Lee and O'Kelly (2011) introduced a competitive location model incorporating a rank proportional choice rule. Also, they explored how the competitive location model with a ranking system differs from other models with two more-typical choice rules-deterministic and probabilistic choices. Wang et al. (2008) addressed the multi-period two-echelon integrated competitive/uncompetitive facility location problem in a distribution system design that involves locating regional distribution centers (RDCs) and stores, and determines the best strategy for distributing the commodities from a central distribution center (CDC) to RDCs and from RDCs to stores. Genetic algorithm-based heuristic (GA) was presented and compared with random search solution and mutually consistent solution (MC).

\subsection{Location-Design models in static environment}

There are many papers in this category which have differences with each other in their assumption and contribution. Brief discussion on each work is addressed in the following.

\subsubsection{Models with inelastic demand}

\section{Continuous models}

Plastria and Carrizosa (2004) introduced a model in which a single facility has to be located and consumers patronize the facility to which they were attracted most. Attraction was stated by some function of the design of the facility and its distance to demand. For existing facilities design was assumed to be fixed, while design of the new facility may be freely chosen at known costs.

Fernandez et al. (2007b) developed two solution methods for a single new facility Huff-like problem. The first model was a repeated local optimization heuristic, extending earlier proposals to the supplementary design question and the presence of locational constraints. The second one was an exact global optimization technique based on reliable computing using interval analysis, incorporating several novel features. Redondo et al. (2008) proposed an evolutionary algorithm called Universal Evolutionary Global Optimizer (UEGO) to cope with the same model. Four parallelization of UEGO have been presented. Redondo et al. (2009a) empirically analyzed several algorithms for solving the same model. In particular, an exact interval branch-and-bound method and a multi-start heuristic was compared with UEGO. Tóth et al. (2009) considered a similar model and proposed an exact interval branch-and-bound algorithm to solve the simultaneous location and design 2-facilities problem. Redondo et al. (2009c) also considered a similar huff-based location problem in which a firm wants to set up two or more new facilities. They analyzed several approaches to solve it; namely, three multi-start local search heuristics, a multi-start simulated annealing algorithm, and two variants of an evolutionary algorithm. The authors researched the behavior of optimal solutions under different environments and changes in the basic model parameters using random problems and a robust evolutionary algorithm for solving this problem in another work (Redondo et al., 2009c). 
Fernandez et al. (2006) presented a hard nonlinear bi-objective optimization problem: detecting the optimal location and design for a new franchised facility within a region where facilities (both of the franchise and not) already exist. The franchisor and the new franchisee both wish to maximize their own profits on the market, but these two objectives are in conflict. An interval branch and bound method were proposed to obtain an outer approximation of the whole set of efficient solutions. Redondo et al. (2014) and Arrondo et al. (2015) implemented a parallelization of multi-objective evolutionary algorithm, called FEMOEA-Paral, for a similar bi-objective competitive facility location and design problem. Fernandez et al. (2007a) proposed another bi-objective optimization problem in which the entrance of the new facility could have a detrimental effect on the market shares of the existing chain-owned facilities, and this cannibalization should be minimized as a secondary objective. A variant of the lexicographic method was proposed to generate certain efficient solutions. Lancinskas et al. (2014) developed a stochastic search algorithm for solving a similar multi-objective competitive facility problem for firm expansion using shared-memory parallel computing systems.

\section{Discrete models}

Kucukaydın et al. (2011a) considered the Huff-based problem in which new facilities were located by a new market entrant firm. They formulated a mixed-integer nonlinear programming model for this problem and proposed three methods for its solution: a Lagrangean heuristic, a branch-and-bound method with Lagrangean relaxation, and another branch-and-bound method with nonlinear programming relaxation.

\subsubsection{Models with elastic demand}

\section{Continuous models}

Redondo et al. (2012) presented a planar problem with variable demand. It has been shown numerically that the assumption of fixed demand influences the location decision, significantly, and therefore the selection of the type of demand (fixed or variable) must be made with care when modeling location problems. Two methods were presented to cope with the model, an exact interval branch-and-bound method and an evolutionary algorithm called UEGO. Arrondo et al. (2014a) proposed a modification of a heuristic to cope with the problem in Redondo et al. (2012), which permits, on the one hand, obtaining the same solutions as the original heuristic more quickly and, on the other hand, to handle larger size problems. Furthermore, a parallel version of the algorithm, suitable for being run in most of today's personal computers, has also been proposed.

\section{Discrete models}

Aboolian et al. (2007a) developed a spatial interaction model for a set of new facilities. The customer demand was assumed to be elastic, expanding as the utility of the service offered by the facilities increases. Increases in the utility can be achieved by increasing the number of facilities, design improvements, or locating facilities closer to the customer. They showed that their model was capable of capturing some of the principal trade-offs involved in facility location and design decisions, including demand cannibalization, market expansion, and design/location trade-offs. An efficient near-optimal solution approach, with adjustable error bound, was developed for the special case where only a finite number of design alternatives are available. Several heuristic approaches capable of handling large instances were also presented.

Drezner et al. (2012) considered two strategies for increasing the market share captured by a chain subject to a budget constraint. One strategy was the improvement of existing facilities and the second one was the construction of new facilities. They analyzed these two strategies as well as the joint strategy which was a combination of the two. A branch and bound procedure and a tabu search heuristic were also constructed for the solution of the unified model. 


\subsection{Location-Price models in static environment}

As stated earlier, in addition to location, another variable of some models is the price of goods or services of facilities. In a static environment there are only three papers worked on location and pricing simultaneously (Pérez et al., 2004; Aboolian et al., 2008; Pelegrín et al., 2014). Perez et al. (2004) studied price competition for two kinds of location-price models in which facility locations were set up and price decisions were made for profit maximization. They discussed the existence and determination of equilibrium prices in a general location space when facilities had different production costs.

Aboolian et al. (2008) presented the problem of optimizing the location and pricing for a set of new service facilities entering a competitive marketplace. They assumed that the new facilities must charge the same (uniform) price and the objective was to optimize the overall profit for the new facilities. Customer demand function was assumed to be elastic; the demand was affected by the price, facility attractiveness, and the travel cost for the highest-utility facility. Pelegrín et al. (2014) studied the problem of locating new facilities for one expanding chain which competes for demand in spatially separated markets where all competing chains use delivered pricing. A location model was proposed for profit maximization of the expanding chain assuming that equilibrium prices were set for each market.

\subsection{Location-other variables models in static environment}

There are three papers on location and some other variables (except price and design) in a static environment (Zhang \& Rushton, 2008; Bozkaya et al., 2010; Konur \& Geunes, 2012). Zhang and Rushton (2008) proposed a multi-site location-allocation model where the objective function maximizes a measure of spatial utility of users subject to constraints on waiting time of users and budget of the multi-site facility owners. The model supports in assisting with decisions by one multi-facility owner about locating new sites or closing current sites in the presence of one or more competitors. Bozkaya et al. (2010) proposed a location-routing model where revenue was realized according to probabilistic patronization of customers and routing costs were incurred due to vehicles serving the open facilities from a central depot. They proposed a hybrid heuristic optimization methodology for solving the model. Konur and Geunes (2012) studied a set of heterogeneous competitive firms simultaneously locating facilities at a set of locations. Firms incur firm-specific transportation, congestion, and location costs, and market price was linear and decreasing in the amount shipped to the market by all firms. A heuristic method has been provided for finding equilibrium locations.

\subsection{Location models in competition with foresight environment}

There are several models considered pure location problems in competition with foresight environment. Each paper has considered a set of assumptions and introduced a new problem. In the following, brief discerption on each works is addressed.

\subsubsection{Models with inelastic demand}

\section{Continuous models}

Bhadury et al. (2003) developed two heuristics for solving the leader-follower problem with closest rule. The methods have been based on the alternating step. Davydov et al. (2014a) developed a local search heuristic for the same problem, based on the VNS framework. Dasci \& Laporte (2005) presented a similar model to determine the location strategies of two retail firms planning to open a number of stores in a geographical market. Firms attempt to maximize their profit under a leader-follower type competition in which the number of stores is made endogenous by the introduction of fixed costs.

Sáiz et al. (2009) modeled the Huff-like problem of two firms that intends to build a single new facility. They developed a branch-and-bound approach for solving the resulted model. Essentially, the bounding was based on the zero sum concept: when there is a gain for one chain there is a loss for the other. 
Shiode et al. (2012) considered a model in which three companies, that are mutually competitive, intend to locate their facilities on a linear market. They presented the optimal location strategies for three facilities. They assumed that the demands are continuously distributed in a linear market and the facilities are locating according to a specific order of sequence.

\section{Discrete models}

Plastria and Vanhaverbeke (2008) adapted the single new facility competitive location model with closest rule. The objective has been to locate facilities under a budget constraint in order to maximize the remaining market share after the competitor's later entry. They developed mixed zero-one programming formulations for each of the following three strategies: the maxmin strategy, the minimum regret strategy, and the von Stackelberg strategy. Alekseeva et al. (2013) provided an exact iterative method for the same problem. They used a local search algorithm at each iteration to find a feasible solution for a system of constraints. Davydov et al. (2014b) proposed two numerical approaches for the same problem: local search with variable neighborhoods and stochastic tabu search. They tried to improve the methods' efficiency at no loss to the quality of the resulting solutions. Biesinger et al. (2014a) proposed a hybrid genetic algorithm for the same problem. The heuristic approach was based on a genetic algorithm with tabu search as local improvement procedure and a complete solution archive. The archive was used to store and convert already visited solutions in order to avoid costly unnecessary re-evaluations. The authors in another work considered six different customer behavior scenarios for the discrete leaderfollower problem (Biesinger et al., 2014c). They presented mixed integer linear programming models for the follower problem of each scenario and used them in combination with an evolutionary algorithm to optimize the location selection for the leader.

Beresnev (2009) studied the leader-follower problem with deterministic utility rule. Some formulations of the problem in the form of two-level integer linear programming problem and, equivalently, as pseudoBoolean two-level programming problem has been proposed. They suggested a method of constructing some upper bounds for the objective functions of the competitive facility location problem. Beresnev and Mel'nikov (2011) proposed a different method for obtaining an upper bound for the same problem. They proposed some local search algorithms for improving the initial approximate solutions. Beresnev (2012) in another work suggested a method for calculating the upper bounds of values of the goal function of the problem at optimal cooperative and noncooperative solutions. Simultaneously with the calculation of the upper bound, the initial approximate solution has been set up. The author in another research proposed a branch-and-bound algorithm for finding the optimal noncooperative solution (Beresnev, 2013). While constructing the algorithm, the model as the problem of maximizing a pseudo-Boolean function was presented. An important ingredient of the algorithm calculated an upper bound for the values of the pseudo- Boolean function on subsets of solutions. On the other hand, Mel'nikov (2014) proposed a randomized local search scheme that employs an internal local search procedure to estimate the solutions being enumerated for the similar problem. In other work, MirHassani et al. (2015) presented a simple and effective nested strategy based on the quantum binary particle swarm optimization (QBPSO) method for solving the similar bi-level mathematical model of the problem. Rahmani and Yousefikhoshbakht (2012) formulated a bi-level fractional mixed-integer nonlinear programming model in which the fixed cost and transportation cost are incorporated.

Ashtiani et al. (2011) presented a leader-follower model with huff-based choice rule. A heuristic method was proposed by them and computational results indicated that the proposed method was efficient for large scale problems. Ramezanian and Ashtiani (2011) solved the same problem via an exact solution method. Biesinger et al. (2014b) presented an evolutionary algorithm with an embedded tabu search to solve the same problem. A complete solution archive has been used to detect already visited candidate solutions and convert them into not yet considered ones. Drezner et al. (2015) investigated a leaderfollower model based on the concept of cover. Each facility attracts consumers within a "sphere of influence" defined by a "radius of influence." The leader and the follower, each has a budget to be spent on the expansion of their chains either by improving their existing facilities or constructing new ones. 
Kononov et al. (2009) considered two classes of leader-follower models, in which several competitors sequentially or simultaneously open new facilities. The first class consisted of discrete two-level programming models. The second class consisted of game models with several independent competitors pursuing selfish goals. Ashtiani et al. (2013) proposed a model with huff-based rule for determining the optimal locations for the leader's new facilities under the condition that the number of the follower's new facilities is unknown for the leader. "Robust Optimization" has been used for maximizing the leader's market share and making the obtained results "robust" in various scenarios in terms of different numbers of the follower's new facilities. Godinho and Dias (2010) studied a problem in which two decision makers will have to decide where to locate their own facilities simultaneously, unsure about the decisions of one another, The authors presented the problem in a franchising environment. They presented an algorithmic approach that was developed to find Nash equilibria. The authors in another work presented the similar problem where the consequence of Franchisee's overbidding was considered (Godinho \& Dias, 2013).

\subsubsection{Models with elastic demand}

\section{Continuous models}

Shiode et al. (2009) presented a leader-follower problem with closest rule in which the demand of each customer depends on the facilities. The distances between the facilities and the demand points were measured by rectangular distance. At first they considered the linear model and derived the optimal policy for locating the facilities. They extended the model to planar case and also derived the optimal policy.

\section{Discrete models}

Biesinger et al. (2014c) considered six different customer behavior and demand scenarios. They presented mixed integer linear programming models for the follower problem of each scenario and used them in combination with an evolutionary algorithm to optimize the location selection for the leader.

\subsection{Location-Design models in competition with foresight environment}

There are few papers in this category which have difference with each other in their assumption and contribution.

\subsubsection{Models with inelastic demand}

\section{Continuous models}

Redondo et al. (2010) presented a huff-based model in which the leader wants to set up a single new facility and the follower will react by locating another single facility after the leader locates its own facility. Four heuristics were proposed for this hard-to-solve global optimization problem, namely, a grid search procedure, an alternating method and two evolutionary algorithms. Hendrix (2015) considered a competitive location with deterministic utility rule. To study this situation, a game theoretic model was formulated and a Stackelberg equilibrium was reached. Saidani et al. (2012) proposed a huff-based model where a two-stage method was developed, which takes into account the reactions of the competitors. In the design decision stage, the competitive decision process occurring among facilities was modelled as a game, whose solution was given by its Nash equilibrium. The solution, which can be represented as functions of the location of the new facility, was obtained by analytical resolution of a system of equations in the case of one facility in the market or by polynomial approximation in the case of multiple facilities. In the location decision stage, an interval based global optimization method was used to determine the best location of the new facility. Saiz et al. (2011) described the location-design decision of a facility for two firms in a new market by a Huff-like attraction model where the profit that can be reached by each firms depends on the actions of its competitor. They studied the profit maximization problem of the firms under different choice rules, assuming that they make their decisions simultaneously. 


\section{Discrete models}

Kucukaydin et al. (2011b) considered a problem in which a firm or franchise enters a market by locating new facilities. The competitor, on the other hand, can react by adjusting the design of its existing facilities with the objective of maximizing its own profit. They formulated a bi-level mixed-integer nonlinear programming model. In order to find the optimal solution of this model, they converted it into an equivalent one-level mixed-integer nonlinear program so that it could be solved by global optimization methods. The authors in another work presented the similar problem in which the competitor can react by opening new facilities, closing existing ones, and adjusting the design levels of its existing facilities, with the aim of maximizing its own profit (Küçükaydın et al., 2012).

\subsubsection{Models with elastic demand}

\section{Continuous models}

Redondo et al. (2013) studied a huff-based competitive location in which the demand varies depending on the attraction for the facilities. Three heuristic methods were proposed to cope with this problem, namely, a grid search procedure, a multistart algorithm and a two-level evolutionary algorithm. Arrondo et al. (2014b) proposed three parallelizations of a subpopulation-based evolutionary algorithm called TLUEGO, a distributed memory programming algorithm, a shared memory programming algorithm, and a hybrid of the two previous algorithms to solve the same problem.

\section{Discrete models}

Wang and Ouyang (2013) presented game-theoretical models based on a continuous approximation (CA) scheme to optimize service facility location design under spatial competition and facility disruption risks. The customer demand in a market depends on the functionality of service facilities and the presence of nearby competitors, as customers normally seek the nearest functioning facility for service. They first analyzed the existence of Nash equilibria in a symmetric two-company competition case. Then they built a leader-follower Stackelberg competition model to derive the optimal facility location design when one of the companies has the first mover advantage over its competitor.

\subsection{Location-Price models in competition with foresight environment}

There are three studies modeled a location-price problem in competition with foresight environment (Fischer, 2002; Panin et al., 2014; Fernández et al., 2014). Fischer (2002) introduced two models for duopolistic competitive discrete location planning with sequential acting and variable delivered prices. If locations and prices are assumed to be set "once and for all” by the competitors, the resulting bi-level program is nonlinear. Under the assumption that further price adjustments are possible, i.e., that a Nash equilibrium in prices was reached, the model could be simplified to a linear discrete bi-level formulation. For the situation with price adjustments, a heuristic solution procedure was suggested. Panin et al. (2014) proposed different models for competitive facility location and pricing as bi-level Boolean linear programming problems. They obtained results that characterize the complexity of the problem where a monopolist's profit on each of the markets is defined with a monotone non-increasing function of the servicing cost. They also proposed two approximate algorithms based on the ideas of alternating heuristics and local search. Fernández et al. (2014) investigated the problem of finding location equilibria of a location-price game where firms first select their locations and then set delivered prices in order to maximize their profits. They proposed an exact interval branch-and-bound algorithm suitable for small and medium size problems and an alternating Weiszfeld-like heuristic for larger instances.

\subsection{Location-other variables models in competition with foresight environment}

There is only one study in this category accomplished by Kwasnica and Stavrulaki (2008), which explored how two firms locate and set capacities to serve time-sensitive customers. Because customers 
are time-sensitive, they may decline to place an order from either competitor if their expected waiting time is large. The authors developed a two-stage game where firms set capacities and then locations.

\section{Conclusion}

Competitive facility location models are very useful in many situations where locations for competing facilities are sought. In this paper, we have presented an overview of competitive facility location papers from 2000 to 2015. As was observed in the previous sections, some of the concepts were less considered and they could be considered for future studies. For example, relocation and redesign of old facilities in addition to opening new ones is applicable in reality and can be considered in the future models. In addition, there is an interest in considering different decision variables besides location. As one of the other future research suggestions, we propose to further investigate cover-based models in the context of competitive location. In fact, the cover approach can be applied to other competitive objectives or analyzed in different environments.

\section{References}

Aboolian, R., Berman, O., \& Krass, D. (2007a). Competitive facility location and design problem. European Journal of Operational Research, 182(1), 40-62.

Aboolian, R., Berman, O., \& Krass, D. (2007b). Competitive facility location model with concave demand. European Journal of Operational Research, 181(2), 598-619.

Aboolian, R., Berman, O., \& Krass, D. (2008). Optimizing pricing and location decisions for competitive service facilities charging uniform price. Journal of the Operational Research Society, 59(11), 1506-1519.

Aboolian, R., Berman, O., \& Krass, D. (2009). Efficient solution approaches for a discrete multi-facility competitive interaction model. Annals of Operations Research, 167(1), 297-306.

Alekseeva, E., Kochetov, Y., \& Plyasunov, A. (2013). An exact method for the discrete (r| p)-centroid problem. Journal of Global Optimization, 1-16.

Arrondo, A. G., Fernández, J., Redondo, J. L., \& Ortigosa, P. M. (2014a). An approach for solving competitive location problems with variable demand using multicore systems. Optimization Letters, 8(2), 555-567.

Arrondo, A. G., Redondo, J. L., Fernández, J., \& Ortigosa, P. M. (2014b). Solving a leader-follower facility problem via parallel evolutionary approaches. The Journal of Supercomputing, 70(2), 600-611.

Arrondo, A. G., Redondo, J. L., Fernández, J., \& Ortigosa, P. M. (2015). Parallelization of a non-linear multiobjective optimization algorithm: Application to a location problem. Applied Mathematics and Computation, 255, 114-124.

Ashtiani, M., Makui, A., \& Ramezanian, R. (2011). Huff-type competitive facility location model with foresight in a discrete space. Management Science Letters, 1(1), 1-12.

Ashtiani, M. G., Makui, A., \& Ramezanian, R. (2013). A robust model for a leader-follower competitive facility location problem in a discrete space. Applied Mathematical Modelling, 37(1), 62-71.

Bello, L., Blanquero, R., \& Carrizosa, E. (2011). On minimax-regret Huff location models. Computers \& Operations Research, 38(1), 90-97.

Benati, S., \& Hansen, P. (2002). The maximum capture problem with random utilities: Problem formulation and algorithms. European Journal of Operational Research, 143(3), 518-530.

Beresnev, V. L. (2009). Upper bounds for objective functions of discrete competitive facility location problems. Journal of Applied and Industrial Mathematics, 3(4), 419-432.

Beresnev, V. L. (2012). Local search algorithms for the problem of competitive location of enterprises. Automation and Remote Control, 73(3), 425-439.

Beresnev, V. (2013). Branch-and-bound algorithm for a competitive facility location problem. Computers \& Operations Research, 40(8), 2062-2070.

Beresnev, V. L., \& Mel'nikov, A. A. (2011). Approximate algorithms for the competitive facility location problem. Journal of Applied and Industrial Mathematics, 5(2), 180-190.

Berman, O., \& Krass, D. (2002). Locating multiple competitive facilities: spatial interaction models with variable expenditures. Annals of Operations Research, 111(1-4), 197-225.

Bhadury, J., Eiselt, H. A., \& Jaramillo, J. H. (2003). An alternating heuristic for medianoid and centroid problems in the plane. Computers \& Operations Research, 30(4), 553-565.

Bhattacharya, B. B., \& Nandy, S. C. (2013). New variations of the maximum coverage facility location problem. European Journal of Operational Research, 224(3), 477-485. 
Biesinger, B., Hu, B., \& Raidl, G. (2014a). A hybrid genetic algorithm with solution archive for the discrete (r|p)centroid problem. Journal of Heuristics, 1-41.

Biesinger, B., Hu, B., \& Raidl, G. (2014b). An evolutionary algorithm for the leader-follower facility location problem with proportional customer behavior. In Learning and Intelligent Optimization (pp. 203-217). Springer International Publishing.

Biesinger, B., Hu, B., \& Raidl, G. (2014c). Models and algorithms for competitive facility location problems with different customer behavior. Annals of Mathematics and Artificial Intelligence, 1-27.

Bozkaya, B., Yanik, S., \& Balcisoy, S. (2010). A GIS-based optimization framework for competitive multi-facility location-routing problem. Networks and Spatial Economics, 10(3), 297-320.

Dasci, A., \& Laporte, G. (2005). A continuous model for multistore competitive location. Operations Research, 53(2), 263-280.

Davydov, I., Kochetov, Y., \& Carrizosa, E. (2014a). A Local Search Heuristic for the (r| p)-Centroid Problem in the Plane. Computers \& Operations Research, 52, 334-340.

Davydov, I. A., Kochetov, Y. A., Mladenovic, N., \& Urosevic, D. (2014b). Fast metaheuristics for the discrete (r| p)-centroid problem. Automation and Remote Control, 75(4), 677-687.

Drezner, T. (2009). Location of retail facilities under conditions of uncertainty. Annals of Operations Research, 167(1), 107-120.

Drezner, T. (2010). Cannibalization in a competitive environment. International Regional Science Review, 0160017610389328.

Drezner, T. (2014). A review of competitive facility location in the plane. Logistics Research, 7(1), 1-12.

Drezner, T., \& Drezner, Z. (2002). Retail facility location under changing market conditions. IMA Journal of Management Mathematics, 13(4), 283-302.

Drezner, T., \& Drezner, Z. (2004). Finding the optimal solution to the Huff based competitive location model. Computational Management Science, 1(2), 193-208.

Drezner, T., \& Drezner, Z. (2008). Lost demand in a competitive environment. Journal of the Operational Research Society, 59(3), 362-371.

Drezner, T., \& Drezner, Z. (2012). Modelling lost demand in competitive facility location. Journal of the Operational Research Society, 63(2), 201-206.

Drezner, T., \& Drezner, Z. (2014). Sequential location of two facilities: comparing random to optimal location of the first facility. Annals of Operations Research, 1-14.

Drezner, T., Drezner, Z., \& Kalczynski, P. (2011). A cover-based competitive location model. Journal of the Operational Research Society, 62(1), 100-113.

Drezner, T., Drezner, Z., \& Kalczynski, P. (2012). Strategic competitive location: improving existing and establishing new facilities. Journal of the Operational Research Society, 63(12), 1720-1730.

Drezner, T., Drezner, Z., \& Kalczynski, P. (2015). A leader-follower model for discrete competitive facility location. Computers \& Operations Research.

Drezner, T., Drezner, Z., \& Salhi, S. (2002a). Solving the multiple competitive facilities location problem. European Journal of Operational Research, 142(1), 138-151.

Drezner, T., Drezner, Z., \& Shiode, S. (2002b). A Threshold-Satisfying Competitive Location Model. Journal of Regional Science, 42(2), 287-299.

Drezner, Z (1995). Facility location: A survey of applications and theory. Springer, Berlin

Drezner, Z., Suzuki, A., \& Drezner, T. (2007). Locating multiple facilities in a planar competitive environment. Journal of the Operations Research Society of Japan, 50, 249-62.

Eiselt, H. A., Laporte, G., \& Thisse, J. F. (1993). Competitive location models: A framework and bibliography. Transportation Science, 27(1), 44-54.Hotelling, H., (1929), Stability in competition, The Economic Journal. 30, 41-57.

Fernández, J., Pelegrín, B., Plastria, F., \& Tóth, B. (2007a). Planar location and design of a new facility with inner and outer competition: an interval lexicographical-like solution procedure. Networks and spatial economics, 7(1), 19-44.

Fernández, J., Pelegrı, B., Plastria, F., \& Tóth, B. (2007b). Solving a Huff-like competitive location and design model for profit maximization in the plane. European Journal of Operational Research, 179(3), $1274-1287$.

Fernández, J., Salhi, S., \& Boglárka, G. (2014). Location equilibria for a continuous competitive facility location problem under delivered pricing. Computers \& Operations Research, 41, 185-195.

Fernandez, J., Toth, B., Plastria, F., \& Pelegrín, B. (2006). Reconciling franchisor and franchisee: a planar biobjective competitive location and design model. In Recent Advances in Optimization (pp. 375-398). Springer Berlin Heidelberg. 
Fischer, K. (2002). Sequential discrete p-facility models for competitive location planning. Annals of Operations Research, 111(1), 253-270.

Fu, K., Miao, Z., \& Xu, J. (2013). On planar medianoid competitive location problems with manhattan distance. Asia-Pacific Journal of Operational Research, 30(02), 1250050.

Godinho, P., \& Dias, J. (2010). A two-player competitive discrete location model with simultaneous decisions. European Journal of Operational Research, 207(3), 1419-1432.

Godinho, P., \& Dias, J. (2013). Two-player simultaneous location game: Preferential rights and overbidding. European Journal of Operational Research, 229(3), 663-672.

Hendrix, E. M. (2015). On competition in a Stackelberg location-design model with deterministic supplier choice. Annals of Operations Research, 1-12.

Hotelling, H., (1929), Stability in competition, The Economic Journal. 30, 41-57.

Huff D.L., (1964), Defining and estimating a trading area, The Journal of Marketing. 28(3), 34-38.

Kononov, A. V., Kochetov, Y. A., \& Plyasunov, A. V. (2009). Competitive facility location models. Computational Mathematics and Mathematical Physics, 49(6), 994-1009.

Konur, D., \& Geunes, J. (2012). Competitive multi-facility location games with non-identical firms and convex traffic congestion costs. Transportation Research Part E: Logistics and Transportation Review, 48(1), 373385.

Küçükaydın, H., Aras, N., \& Altınel, İ. K. (2011a). A discrete competitive facility location model with variable attractiveness. Journal of the Operational Research Society, 62(9), 1726-1741.

Küçükaydin, H., Aras, N., \& Altınel, I. K. (2011b). Competitive facility location problem with attractiveness adjustment of the follower: A bilevel programming model and its solution. European Journal of Operational Research, 208(3), 206-220.

Küçükaydın, H., Aras, N., \& Altınel, İ. K. (2012). A leader-follower game in competitive facility location. Computers \& Operations Research, 39(2), 437-448.

Kwasnica, A. M., \& Stavrulaki, E. (2008). Competitive location and capacity decisions for firms serving timesensitive customers. Naval Research Logistics (NRL), 55(7), 704-721.

Lančinskas, A., Ortigosa, P. M., \& Žilinskas, J. (2014, January). Parallel Shared-Memory Multi-Objective Stochastic Search for Competitive Facility Location. In Euro-Par 2014: Parallel Processing Workshops (pp. 71-82). Springer International Publishing.

Lee, G., \& O’Kelly, M. E. (2011). Competitive location modeling with a rank proportional allocation. Environment and Planning-Part B, 38(3), 411.

McGarvey, R. G., \& Cavalier, T. M. (2005). Constrained location of competitive facilities in the plane. Computers \& Operations Research, 32(2), 359-378.

Mel'nikov, A. A. (2014). Randomized local search for the discrete competitive facility location problem. Automation and Remote Control, 75(4), 700-714.

Miliotis, P., Dimopoulou, M., \& Giannikos, I. (2002). A hierarchical location model for locating bank branches in a competitive environment. International transactions in operational research, 9(5), 549-565.

MirHassani, S. A., Raeisi, S., \& Rahmani, A. (2015). Quantum binary particle swarm optimization-based algorithm for solving a class of bi-level competitive facility location problems. Optimization Methods and Software, (ahead-of-print), 1-13.

Panin, A. A., Pashchenko, M. G., \& Plyasunov, A. V. (2014). Bilevel competitive facility location and pricing problems. Automation and Remote Control, 75(4), 715-727.

Pelegrín, B., Fernández, P., \& Pérez, M. D. G. (2014). Profit maximization and reduction of the cannibalization effect in chain expansion. Annals of Operations Research, 1-19.

Pelegrín, B., Fernández, P., Pérez, M. D. G., \& Hernández, S. C. (2012). On the location of new facilities for chain expansion under delivered pricing. Omega, 40(2), 149-158.

Pérez, M. D. G., Hernández, P. F., \& Pelegrín, B. P. (2004). On price competition in location-price models with spatially separated markets. Top, 12(2), 351-374.

Plastria, F. (2001). Static competitive facility location: an overview of optimisation approaches. European Journal of Operational Research, 129(3), 461-470.

Plastria, F. (2005). AVOIDING CANNIBALISATION AND/OR CONIPETITOR REACTION EN PLANAR SINGLE FACILITY LOCATION. Journal of the operations research, 48(2), 1484157.

Plastria, F., \& Carrizosa, E. (2004). Optimal location and design of a competitive facility. Mathematical programming, 100(2), 247-265.

Plastria, F., \& Vanhaverbeke, L. (2007). Aggregation without loss of optimality in competitive location models. Networks and spatial economics, 7(1), 3-18. 
Plastria, F., \& Vanhaverbeke, L. (2008). Discrete models for competitive location with foresight. Computers \& Operations Research, 35(3), 683-700.

Rahmani, A., \& Yousefikhoshbakht, M. (2012). Using a Mathematical Multi-facility location Model for the Market Competition.

Ramezanian, R., \& Ashtiani, M. G. (2011). Sequential Competitive Facility Location Problem in a Discrete Planar Space. International Journal of Applied, 1(2), 15-20.

Redondo, J. L., Arrondo, A. G., Fernández, J., García, I., \& Ortigosa, P. M. (2013). A two-level evolutionary algorithm for solving the facility location and design (1|1)-centroid problem on the plane with variable demand. Journal of global optimization, 56(3), 983-1005.

Redondo, J. L., Fernández, J., Arrondo, A. G., García, I., \& Ortigosa, P. M. (2012). Fixed or variable demand? Does it matter when locating a facility?. Omega, 40(1), 9-20.

Redondo, J. L., Fernandez, J., Garcia, I., \& Ortigosa, P. M. (2008). Parallel algorithms for continuous competitive location problems. Optimisation Methods \& Software, 23(5), 779-791.

Redondo, J. L., Fernández, J., García, I., \& Ortigosa, P. M. (2009a). A robust and efficient algorithm for planar competitive location problems. Annals of Operations Research, 167(1), 87-105.

Redondo, J. L., Fernández, J., García, I., \& Ortigosa, P. M. (2009b). Sensitivity analysis of a continuous multifacility competitive location and design problem. Top, 17(2), 347-365.

Redondo, J. L., Fernández, J., García, I., \& Ortigosa, P. M. (2009c). Solving the multiple competitive facilities location and design problem on the plane. Evolutionary Computation, 17(1), 21-53.

Redondo, J. L., Fernández, J., García, I., \& Ortigosa, P. M. (2010). Heuristics for the facility location and design (1) 1)-centroid problem on the plane. Computational Optimization and Applications, 45(1), 111-141.

Redondo, J. L., Fernández, J., Hervás, J. D. Á., Arrondo, A. G., \& Ortigosa, P. M. (2014). Approximating the Pareto-front of a planar bi-objective competitive facility location and design problem. Computers \& Operations Research.

Saidani, N., Chu, F., \& Chen, H. (2012). Competitive facility location and design with reactions of competitors already in the market. European journal of operational research, 219(1), 9-17.

Sáiz, M. E., Hendrix, E. M., Fernández, J., \& Pelegrín, B. (2009). On a branch-and-bound approach for a Hufflike Stackelberg location problem. OR spectrum, 31(3), 679-705.

Sáiz, M. E., Hendrix, E. M., \& Pelegrín, B. (2011). On Nash equilibria of a competitive location-design problem. European Journal of Operational Research, 210(3), 588-593.

Shiode, S., Yeh, K. Y., \& Hsia, H. C. (2009). Competitive Facility Location Problem with Demands Depending on the Facilities. Asia Pacific Management Review, 14(1).

Shiode, S., Yeh, K. Y., \& Hsia, H. C. (2012). Optimal location policy for three competitive facilities. Computers \& Industrial Engineering, 62(3), 703-707.

Tóth, B., Fernández, J., Pelegrín, B., \& Plastria, F. (2009). Sequential versus simultaneous approach in the location and design of two new facilities using planar Huff-like models. Computers \& Operations Research, 36(5), 1393-1405.

Uno, T., Katagiri, H., \& Kato, K. (2009). Facility location problems with random demands in a competitive environment. IAENG International Journal of Applied Mathematics, 39(2), 122-127.

Uno, T., Katagiri, H., \& Kato, K. (2010). A facility location for fuzzy random demands in a competitive environment. IAENG International Journal of Applied Mathematics, 40(3), 172-177.

Uno, T., Katagiri, K., \& Kato, K. (2011). A multi-dimensionalization of competitive facility location problems. Int J Innov Comput Inf Control, 7, 2593-2601.

Wang, X., \& Ouyang, Y. (2013). A continuum approximation approach to competitive facility location design under facility disruption risks. Transportation Research Part B: Methodological, 50, 90-103.

Wang, X. F., Sun, X. M., \& Fang, Y. (2008). Genetic algorithm solution for multi-period two-echelon integrated competitive/uncompetitive facility location problem. Asia-Pacific Journal of Operational Research, 25(01), 33-56.

Zhang, L., \& Rushton, G. (2008). Optimizing the size and locations of facilities in competitive multi-site service systems. Computers \& Operations Research, 35(2), 327-338. 